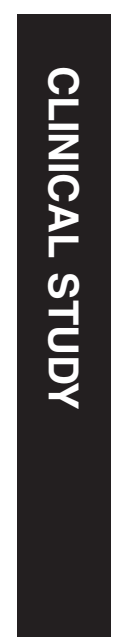

\section{Evaluation of corneal endothelial cell damage after vitreoretinal surgery: comparison of different endotamponades}

E Cinar, MO Zengin and C Kucukerdonmez

cataract surgery were more vulnerable to EC loss than phakic eyes, supporting the protective effect of an intact lens. Eye (2015) 29, 670-674; doi:10.1038/eye.2015.26; published online 13 March 2015

Introduction

Corneal endothelial cell (EC) loss can result from both intrinsic factors, such as trauma, ${ }_{1}^{1}$ ocular surgery, ${ }^{2,3}$ systemic diseases (such as diabetes), ${ }^{4}$ and ultraviolet radiation, ${ }^{5}$ and extrinsic factors, such as age, ${ }^{6}$ race, ${ }^{6}$ gender, ${ }^{7}$ and genetics. ${ }^{8}$ It is known that the repair capacity of corneal ECs is limited and a lack of cell proliferation results in age-related reductions in endothelial cell density $^{9}$ (ECD). A clinical estimate of ECD and function can be provided using specular microscopy, fluorophotometry and pachymetry. Normative data regarding ECD and morphology are thus important, because they facilitate assessment of the functional reserve of the endothelium in individual patients. The analysis provides a measure of the general health of the corneal endothelium, which is important before any intraocular surgery.

It has been demonstrated that the duration of ocular surgery, such as cataract and vitreoretinal surgery, is related to ocular surface damage, such as goblet cell loss and tear film instability, and also EC loss. ${ }^{3,10}$ The corneal complications of vitreoretinal surgery are rarely the primary concern of the surgeon operating on a difficult retinal detachment. However, the surgeon should be aware of which procedures are more likely to induce corneal decompensation, because corneal abnormalities are a common cause of visual loss following an otherwise successful surgery. ${ }^{11}$ However, to 
date, few studies regarding the effects of vitreoretinal surgery on ECs have been performed. Moreover, most studies in the literature concern vitreoretinal surgery with the placement of silicone oil (SO), which has known toxic effects on the corneal endothelium.

The aim of this study was to evaluate the EC damage after vitreoretinal surgery and to compare the results using different tamponades. A quantitative specular microscopic analysis included measurements of mean cell density (MCD) and mean cell area (MCA). Also, measurements of variation in cell size (polymegathism) and cell shape (polymorphism) were examined.

\section{Materials and methods}

This prospective study included 45 eyes of 45 patients ( 24 females, 21 males) who underwent pars plana vitrectomy (PPV) with gas (sulphur hexafluoride $\left(\mathrm{SF}_{6}\right), 20 \%$ ) or SO tamponade at the Department of Ophthalmology, Izmir University Faculty of Medicine, between June 2013 and June 2014. The study observed the tenets of the Declaration of Helsinki. Informed consent was obtained from each patient after a full explanation of the examinations.

Each patient underwent a standard ophthalmological examination, including determination of refractive error, best-corrected visual acuity testing, slit-lamp biomicroscopy, Goldmann applanation tonometry, and funduscopy. Patients who had corneal abnormalities, glaucoma, strabismus, and a previous history of ocular trauma and intraocular surgery (excluding cataract surgery) were excluded.

After routine ophthalmic examinations, all volunteers underwent corneal EC evaluations using a non-contact specular microscopy (SP 2000P; Topcon, Tokyo, Japan). Parameters recorded from the system included MCD (cells $\left./ \mathrm{mm}^{2}\right)$, MCA $\left(\mu \mathrm{m}^{2}\right)$, coefficient of variation $(\mathrm{CV})$ in cell size, and percentage of hexagonal cells (HC). The MCD of the cornea was measured using the centre-dot method at the corneal centre. The CV in cell size (standard deviation divided by the MCA) was used as an index of the extent of variation of the cell area (polymegathism). $\mathrm{HC}$ in the analysed area was used as an index of variation in cell shape (polymorphism). All measurements were obtained at baseline and at 3 months after surgery. The fellow eye in each patient was also evaluated.

PPV was performed under local anaesthesia in all patients by the same experienced surgeon. The technique was as follows. After transconjunctival insertion of a 23gauge infusion port and microcannulas $3.5 \mathrm{~mm}$ behind the inferotemporal, superotemporal, and superonasal limbus, core and peripheral vitrectomies were performed. The posterior hyaloid face was detached, and triamcinolone-assisted internal limiting membrane peeling was performed as needed. Perfluorocarbon liquid (DK-line; Chauvin Opsia, Labege, France) was used as needed, and after exchange with air, the eye was filled with gas $\left(\mathrm{SF}_{6}, 20 \%\right)$ or SO (Dimethicone, 1000 centistokes). In all eyes, the same ophthalmic balanced salt solution (BSS Plus, Alcon Laboratories, Fort Worth, TX, USA) was used as the intraocular irrigating solution. One drop of cold BSS Plus solution was applied to the ocular surface every 30-60s to prevent epithelial damage. Postoperatively, all patients were given antibiotic $(0.5 \%$, oxifloxacin hydrochloride ophthalmic solution, Alcon Laboratories) and steroid eye drops (prednisolone acetate $10 \mathrm{mg} / \mathrm{ml}$; Allergan BV, Nieuwegein, The Netherlands) four times daily for 1 month.

Patients were assigned to one of the three groups: group 1 (phakic and $20 \% \mathrm{SF}_{6}$ gas tamponade), group 2 (pseudophakic and $20 \% \mathrm{SF}_{6}$ gas tamponade), and group 3 (phakic and SO tamponade; Table 1). EC evaluation was performed at the third month postoperatively, when the gas in the vitreous cavity was completely resorbed. In all eyes, the SO was necessary as a long-term tamponade and was not removed during the evaluation period. All pseudophakic patients had cataract surgery at least 6 months before vitrectomy. No additional cataract

Table 1 Preoperative diagnoses and demographic data of patients in each group

\begin{tabular}{lccc}
\hline Diagnosis and demographical data & $\begin{array}{c}\text { Group 1 (phakic, } \\
\text { SF6 gas tamponade) }\end{array}$ & $\begin{array}{c}\text { Group 2 (pseudophakic, } \\
\text { SF6 gas tamponade) }\end{array}$ & $\begin{array}{c}\text { Group 3 (phakic, silicone } \\
\text { oil tamponade) }\end{array}$ \\
\hline Age (years) & $55.3 \pm 11.6$ & $56.8 \pm 10.2$ & $12 / 8$ \\
Sex (female/male) & $5 / 5$ & & $56.7 \pm 14.2$ \\
& & $7 / 8$ \\
Diagnosis & 1 & 6 & 11 \\
Retina detachment & 2 & 7 & 3 \\
Intraocular haemorrhage & 1 & 1 & - \\
Epiretinal membrane & 1 & 2 & - \\
Proliferative vitreoretinopathy & 3 & 3 & - \\
Macular hole & 2 & & \\
Vitreomacular traction & & & - \\
\hline
\end{tabular}


surgery was performed after the vitrectomy during follow-up.

Statistical analyses were performed using the SPSS software (ver. 16.0 for Windows; SPSS Inc., Chicago, IL, USA). For each continuous variable, normality was checked with the Kolmogorov-Smirnov test. As our data showed a distribution outside of the normality curve, the non-parametric Kruskal-Wallis test was used for analysis of variance. Preoperative and postoperative measurements were analysed using the Wilcoxon test. Categorical variables between groups were analysed using the $\chi^{2}$ test. $P$-values $<0.05$ were considered to indicate statistical significance.

\section{Results}

Demographic data for all patients are given in Table 1. The mean ages of patients in groups $1-3$ were $55.3 \pm 11.6$ (mean \pm s.d., range, 40-76) years, $56.8 \pm 10.2$ (range, 50-79) years, and $56.7 \pm 14.1$ (range, 30-71) years, respectively. There was no statistically significant difference among the three groups in age or sex $(P>0.05)$.

Surgical indications for PPV were retinal detachment $(n=13)$, intraocular haemorrhage $(n=11)$, epiretinal membrane $(n=8)$, proliferative vitreoretinopathy $(n=3)$, macular hole $(n=5)$, and vitreomacular traction $(n=5)$ (Table 1).

MCD, MCA, CV, and HC values of all groups at baseline and at postoperative 3 months are shown in Table 2. Statistically significant differences in baseline MCD and MCA values were observed among the groups $(P=0.028$ and $P=0.022$, respectively), and after multiple comparisons sub-group analysis, group 2 , which had the lowest MCD and MCA measurements, was found to be significantly different than the other groups $(P=0.021$ and 0.016). There was no significant difference in baseline $\mathrm{CV}$ or HC (both $P>0.05$ ). No baseline parameter in the study eyes of groups 1 and 3 showed any difference when compared with the fellow eyes. However, study eyes of group 2 (pseudophakic) showed significantly lower baseline MCD, MCA, and HC values than the fellow eyes (all $P<0.05$ ).

At 3 months postoperatively, eyes that underwent surgery in all three groups showed significantly lower MCD, HC, and CV values than baseline (all $P<0.05$ ). However, the MCA readings of both eyes were not statistically different in any group at baseline vs 3 months postoperatively (all $P>0.05$ ). The percentage of changes in MCD at 3 months after PPV were $3.8 \pm 2.8 \%$ in group 1 , $8.0 \pm 7.5 \%$ in group 2 , and $4.6 \pm 5.4 \%$ in group 3 , respectively. The difference in group 2 was significantly higher than the other groups $(P=0.029)$.

The fellow eyes showed a change in MCD, which was $0.31 \pm 1.41 \%$ in group $1,-0.63 \pm 1.90 \%$ in group 2 , and

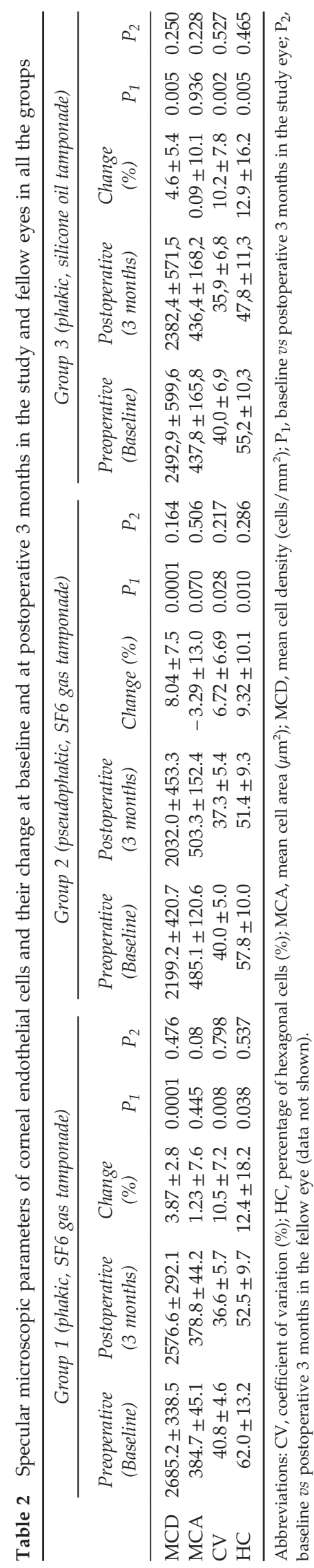


$0.14 \pm 0.52 \%$ in group 3 at 3 months postoperatively. The differences were not significant in all groups (all $P>0.05$ ).

\section{Discussion}

In this study, we found significant EC loss in all groups after vitrectomy surgery at 3 months, demonstrated in terms of MCD, CV, and HC. The difference was significantly higher in the pseudophakic group (group 2) than the other groups, with a mean reduction of $8.0 \pm 7.5 \%$ in MCD. There was no statistically significant difference in mean MCD values of the fellow eyes in each group, which served as controls.

Intraocular SO tamponade is used widely for the repair of complex cases of retinal detachment. ${ }^{12}$ One of the disadvantages of $\mathrm{SO}$ endotamponade is a risk of secondary increase in intraocular pressure, leading to acute pupillary block glaucoma or to secondary openangle glaucoma and EC cell loss. ${ }^{13,14}$ Other reports have described EC loss as a relatively common complication after PPV and SO injection. ${ }^{15,16}$ The most recent study regarding EC loss after vitrectomy was reported by Goezinne et al, ${ }^{17}$ who investigated five groups of patients. According to their results, the highest loss in EC at postoperative 12 months was observed in aphakic eyes $(39.2 \%)$, followed by pseudophakic eyes (19.2\%) that underwent cataract surgery during the follow-up period. The eyes that were pseudophakic at the beginning of the study showed an EC loss of $4.6 \%$. However, phakic eyes showed no significant difference. The SO tamponade eyes in our study included only phakic eyes, in which a statistically significant reduction $(4.6 \%)$ in MCD at 3 months postoperatively was found, compared with baseline.

Rosenfeld et al ${ }^{18}$ reported a reduction of ECD at 6 months postoperatively in both aphakic eyes (13\%) and eyes undergoing lensectomy combined with PPV $(17 \%)$, compared with phakic eyes $(0.4 \%)$. In another recent prospective study on ECD after PPV without SO tamponade, Friberg et al ${ }^{16}$ reported a significant ECD reduction in aphakic eyes and in eyes that underwent simultaneous lensectomy, with or without gas-fluid exchange, compared with patients undergoing scleral buckling alone. No EC loss was found in phakic eyes undergoing PPV without lens removal. ${ }^{16}$ These authors hypothesized that the intact lens may protect the corneal endothelium during PPV and that fluid-gas exchange may be harmful in aphakic eyes. ${ }^{16}$

Gas introduced into the eye following vitrectomy can also damage the endothelium; the effects of $\mathrm{SF}_{6}$ gas are probably similar to those of air, but perfluoropentane $\left(\mathrm{C}_{5} \mathrm{~F}_{12}\right)$ has been shown to be more toxic because it resorbs slower. ${ }^{19-23}$ Schulze et $a l^{24}$ showed that morphological cell changes occurred after $\mathrm{SF}_{6}$ injection in the anterior chamber of rabbit eyes. The effects of $\mathrm{C}_{3} \mathrm{~F} 8$ gas on corneal ECs in rabbits was also evaluated in a more recent study in which the authors found that the $20 \%$ concentration of the gas caused significant decreases in EC density vs 15 and $10 \%$ levels. ${ }^{25}$ Another experimental study on rabbits demonstrated that the longer-acting gas tamponades yielded more disruption in corneal EC permeability and function. ${ }^{26}$ Clinical studies investigating the effects of intraocular gas tamponades on corneal endothelium showed similar results. Friberg and Guibord ${ }^{16}$ reported a mean cell loss of $16.9 \%$ in patients who received $\mathrm{SF}_{6}$ gas after vitrectomy and lensectomy. This result was comparable with the findings of Mitamura et al, ${ }^{27}$ who also demonstrated a mean cell loss of $17.2 \%$ at 6 months after surgery in such patients. Moreover, the latter study also evaluated EC loss after the use of $\mathrm{C}_{3} \mathrm{~F}_{8}$ tamponade in patients who underwent vitrectomy with total or capsulepreserved lensectomy. They found that the EC loss was significantly lower in eyes with an intact anterior capsule (27.5 vs 3.5\%). Our study included eyes in which $\mathrm{SF}_{6}$ at $20 \%$ was used as the tamponading agent, and we found a mean EC loss of $3.8 \%$ in phakic and $8.0 \%$ in pseudophakic eyes. Although the same tamponade was used in both the groups, the lower EC loss in phakic patients might be due to the protective effect of the intact lens. Moreover, the amount of cell loss in pseudophakic patients was comparable with previous studies, consistent with a role of an intact lens or lens capsule in preventing damage to ECs.

This study had several limitations. Major limitations were the lack of EC counts at consecutive follow-up visits and the relatively low number of patients in each group. Moreover, the surgery time was not measured, which is also considered a confounding factor, leading to EC loss. The imbalance between the indications for PPV surgery between groups may also have an indirect effect on EC loss, because the number of patients with retinal detachment in the SO group was higher than the other groups, which probably required longer surgery times. Although several other shortcomings of this preliminary study exist, such as the lack of pseudophakic eyes in the SO placement group, the use of only a short-acting gas tamponade $\left(\mathrm{SF}_{6}\right)$, and the lack of grading $\mathrm{SO}$ emulsification, the results are valuable due to the singlecentre, single-surgeon design and homogenity of patient ages among groups. Also, EC measurements were obtained by the same examiner who conducted a minimum of 50 EC counts in each patient, which is above the suggested limit to obtain an accurate measurement. ${ }^{28}$ Additionally, that the anterior chamber was not entered during PPV in any patient makes it possible to exclude any negative effect of lens surgery on EC. 
In conclusion, $\mathrm{PPV}$ with gas $\left(\mathrm{SF}_{6}\right)$ or $\mathrm{SO}$ endotamponade resulted in a significant decrease in EC, which was highest in pseudophakic eyes. The suggested hypothesis of EC protection by an intact lens was supported by the findings of this study. Moreover, the lower, but significant, loss of EC in eyes with SO showed that even if an intact lens exists, the possibility of SO toxicity is still present and early SO removal should be considered if the patient has low preoperative EC counts. Several confounding factors, such as phototoxicity, fluid turbulence, $\mathrm{pH}$, and temperature changes, may affect the corneal endothelium during surgery. Thus, long-term controlled studies are needed to assess the potential anterior segment 'side effects' of posterior segment surgeries.

\section{What was known before}

- Vitreoretinal surgery does harm corneal endothelium.

\section{What this study adds}

- Both silicone oil and gas reduces corneal endothelial cell count, without a significant difference between them. The protective effect of an intact lens has been observed.

\section{Conflict of interest}

The authors declare no conflict of interest.

\section{References}

1 Slingsby JG, Forstot SL. Effect of blunt trauma on the corneal endothelium. Arch Ophthalmol 1981; 99: 1041-1043.

2 Dutt S, Steinert RF, Raizman MB, Puliafito CA. One-year results of excimer laser photorefractive keratectomy for low to moderate myopia. Arch Ophthalmol 1994; 112: 1427-1436.

3 Oh T, Jung Y, Chang D, Kim J, Kim H. Changes in the tear film and ocular surface after cataract surgery. Jpn J Ophthalmol 2012; 56: 113-118.

4 Schultz RO, Matsuda M, Yee RW, Edelhauser HF, Schultz KJ. Corneal endothelial changes in type I and type II diabetes mellitus. Am J Ophthalmol 1984; 98: 401-410.

5 Michels M, Sternberg P Jr. Operating microscope-induced retinal phototoxicity: pathophysiology, clinical manifestations and prevention. Surv Ophthalmol 1990; 34: 237-252.

6 Padilla MD, Sibayan SA, Gonzales CS. Corneal endothelial cell density and morphology in normal Filipino eyes. Cornea 2004; 23: 129-135.

7 Rao SK, Ranjan Sen P, Fogla R, Gangadharan S, Padmanabhan P, Badrinath SS. Corneal endothelial cell density and morphology in normal Indian eyes. Cornea 2000; 19: $820-823$.

8 Makitie J, Vannas A., Koskenvuo M. Corneal endothelial cells in mono- and di-zygotic twins. Invest Ophthalmol Vis Sci 1983; 24: 1029-1032.

9 Ko MK, Park WK, Lee JH, Chi JG. A histomorphometric study of corneal endothelial cells in normal human fetuses. Exp Eye Res 2001; 72: 403-409.
10 Hwang HB, Kim HS. Phototoxic effects of an operating microscope on the ocular surface and tear film. Cornea 2014; 33: 82-90.

11 Paris MP, Peyman GA, Kao GW. Early anterior sagment complications after silicone oil injectio. Can J Ophthalmol 1986; 21: 271-275.

12 Azen SP, Scott IU, Flynn HW Jr, Lai MY, Topping TM, Benati L et al. Silicone oil in the repair of complex retinal detachments. A prospective observational multicenter study. Ophthalmology 1998; 105: 1587-1597.

13 Henderer JD, Budenz DL, Flynn HW Jr, Schiffman JC, Feuer WJ, Murray TG. Elevated intraocular pressure and hypotony following silicone oil retinal tamponade for complex retinal detachment: incidence and risk factors. Arch Ophthalmol 1999; 117: 189-195.

14 Honavar SG, Goyal M, Majji AB, Sen PK, Naduvilath T, Dandona L. Glaucoma after pars plana vitrectomy and silicone oil injection for complicated retinal detachments. Ophthalmology 1999; 106: 169-176.

15 Friberg TR, Doran DL, Lazenby FL. The effect of vitreous and retinal surgery on corneal endothelial cell density. Ophthalmology 1984; 91: 1166-1169.

16 Friberg TR, Guibord NM. Corneal endothelial cell loss after multiple vitreoretinal procedures and the use of silicone oil. Ophthalmic Surg Lasers 1999; 30: 528-534.

17 Goezinne F, Nuijts RM, Liem AT, Lundqvist IJ, Berendschot TJ, Cals DW. Corneal endothelial cell density after vitrectomy with silicone oil for complex retinal detachments. Retina 2014; 34: 228-236.

18 Rosenfeld SI, Waltman SR, Olk RJ, Gordon M. Comparison of intraocular irrigating solutions in pars plana vitrectomy. Ophthalmology 1986; 93: 109-115.

19 Van Horn DL, Edelhauser HF, Aaberg TM, Pederson HJ. In vivo effects of air and sulfa hexafluoride gas on rabbit corneal endothelium. Invest Ophthalmol Vis Sci 1972; 11: 1028-1036.

20 Leibowitz HM, Laing RA, Sandstrom M. Corneal endothelium: the effect of air in the anterior chamber. Arch Ophthalmol 1974; 92: 227-230.

21 Olson RJ. Air and the corneal endothelium. Arch Ophthalmol 1980; 98: 283-284.

22 Eiferman RA, Wilkins EL. The effect of air on human corneal endothelium. Am J Ophthalmol 1981; 92: 328-331.

23 Foulks GN, De Juan E, Hatchell DL, McAdoo T, Hardin J. The effect of perfluoropentane on the cornea in rabbits and cats. Arch Ophthalmol 1987; 105: 256-259.

24 Schulze F, Schmidtsdorf H. Damage to the corneal endothelium following exposure to sulfur hexafluoride gas. Klin Monbl Augenheilkd 1989; 194: 447-453.

25 Jee DH, Kim HS. The effect of $\mathrm{C}_{3} \mathrm{~F}_{8}$ gas on corneal endothelial cells in rabbits. Jpn J Ophthalmol 2010; 54: 602-608

26 Green K, Cheeks L, Stewart DA, Trask D. Role of toxic ingredients in silicone oils in the induction of increased corneal endothelial permeability. Lens Eye Toxic Res 1992; 9: 377-338.

27 Mitamura Y, Yamamoto S, Yamazaki S. Corneal endothelial cell loss in eyes undergoing lensectomy with and without anterior lens capsule removal combined with pars plana vitrectomy and gas tamponade. Retina 2000; 20: 59-62.

28 Benetz BA, Diaconu E, Bowlin SJ, Oak SS, Laing RA, Lass JH. Comparison of corneal endothelial image analysis by Konan SP8000 noncontact and Bio-Optics Bambi systems. Cornea 1999; 18: 67-72. 